\title{
Trends in the development of technical means for recycling organic waste from agricultural production
}

\author{
Ludmila Kachanova ${ }^{1, *}$, Anatoly Bondarenko ${ }^{2}$, and Alexander Golovko ${ }^{2}$ \\ ${ }^{1}$ Don State Technical University, 344002, Gagarina sq., 1, Rostov-on-Don, Rostov reg., Russia \\ ${ }^{2}$ Azov-Black Sea Engineering Institute of Don State Agrarian University, 347740, Lenina st., 21, \\ Zernograd, Rostov reg., Russia
}

\begin{abstract}
Obtaining record harvests of grain crops in Russia in recent years has led to a decrease in soil fertility and degradation of agricultural lands. More than 40 million hectares of arable land require restoration. The lack of organic raw materials does not contribute to the restoration of soil fertility, and the manure and manure produced are the main sources of environmental pollution. The purpose of the work was to develop trends in the development of technical means for recycling organic waste from agricultural production. The main method for achieving the goal was a systematic analysis of literary sources on this topic and the results of the authors' own research. The results of the recycling of liquid, semi-liquid and solid manure into concentrated organic fertilizers are given. The main development trends: the ability to interact with animal husbandry and crop production; transfer of raw materials (organic waste of animal husbandry and crop production) into a product in the form of high-quality concentrated organic fertilizers, necessary for the restoration of soil fertility; digitalization of technological processes for the production of KOU and their differentiated application to the field by scanning the qualitative composition of nutrients in the production layer of the soil.
\end{abstract}

\section{Introduction}

In the context of globalization of the world economy, the most important task of the state is to maintain the parity of its food security. At the first stage, it is required to reduce the import substitution indicator (in the Russian Federation in 2014 it amounted to 38\%) to $15-20 \%$, thereby reducing the dependence of industry and agriculture on foreign equipment and food imports. In the context of many years of application of sanctions by leading foreign states against the Russian Federation, domestic manufacturers successfully cope with the task of supplying leading industries with domestically produced machines and mechanisms.

\footnotetext{
*Corresponding author: kachanovakls@mail.ru
} 
Ensuring food security is based on the successful functioning of the basic sectors of the agro-industrial complex: crop and livestock production. In 2019, a record harvest of grain crops in the amount of 119 million tons was harvested in the Russian Federation. In 2020, it is planned to harvest 120.5 million tons of grain crops. Obtaining high yields is accompanied by the removal of significant amounts of nutrients from the soil and, as a result, its depletion.

Currently, the arable land in the Russian Federation is more than 190 million hectares, of which about $85 \%$ is subject to varying degrees of water and wind erosion, which leads to an annual shortage of more than 25 million tons of grain. In recent years, about 40 million hectares of arable land have been removed from the general crop rotation and require significant financial costs for their restoration.

One of the main grain-producing regions of the Russian Federation is the Southern Federal District. In the structure of the lands of the Southern Federal District by categories, agricultural lands account for $78.4 \%$ (33,012 thousand ha).

With regard to the main constituent entity of the Southern Federal District - Rostov region - in the structure of agricultural land (10,097 thousand hectares) agricultural land is 8512.4 thousand hectares $(84.3 \%)$, including arable land -5867 thousand hectares $(58.1 \%)$ $[1,2]$. In these areas, over the past three decades, the destabilization of the crop industry has been observed, including in connection with a significant decrease in effective soil fertility due to the use of extensive technologies for the production of crop products [1]. Decrease in effective soil fertility predetermined their degradation. Of the many reasons for the increase in the number of degraded areas in the total arable land, the main one is the deterioration of the structure of the productive soil layer and a decrease in its fertility due to insufficient application of organic fertilizers, as the basis for the restoration of soil fertility [3].

The main source of organic fertilizer production is manure from livestock enterprises, poultry manure, organic waste from crop production. At livestock and poultry enterprises, depending on the technologies for keeping animals and poultry, liquid, semi-liquid and bedding manure (dung) is produced.

The existing technologies for recycling these organic waste with their conversion into high-quality organic fertilizers are ineffective and do not meet environmental requirements during their storage and further processing into fertilizers. The issues of recycling organic waste from animal husbandry (poultry farming) are currently not resolved in any country in the world. Attempts to copy technologies and technical means of processing organic waste without taking into account the natural and climatic conditions of the regions are fraught with a violation of the ecological situation in the places of their accumulation and use and do not give a tangible effect as an organic fertilizer to increase soil fertility [4].

\section{Materials and methods.}

The economic effect of recycling organic waste can be objectively obtained with a systematic approach to the functioning of the crop and livestock industries. The systematic approach and the systemic analysis based on it in relation to the problems of soil fertility allow to study the state and the reasons for its deterioration, to substantiate the tools for improving the situation, to proceed to the development of new technologies and technical means to solve the problem. The main crop production is the cultivation of grain crops and row crops, vegetables, etc. The quality and quantity of products grown depends on the state of soil fertility and the technologies used for their production. The main livestock products are milk, meat, wool, etc. Manure produced at livestock and poultry enterprises in the legislative framework of the Russian Federation is defined as waste of IV and V hazard classes [4]. According to the Ministry of Natural Resources of Russia, manure, droppings and other 
organic substances and materials formed in animal husbandry as a result of keeping farm animals and are products of the latter's life, after their disinfection in accordance with sanitary rules, as well as organic fertilizers produced on their basis, can be sold as products if the following conditions are met:

- in the presence of statutory, design, technological and other documentation that allows to classify manure, droppings, other organic substances formed at the enterprise as a result of economic activities, to products;

- in the presence of developed and approved technical conditions for fertilizers based on manure, droppings, other organic substances, which take into account state and industry standards, sanitary and hygienic standards and rules, environmental requirements, as well as in the presence of technological regulations for manure, droppings, organic substances and materials;

- when reflecting in the economic, accounting records of the enterprise operations with the specified manure, dung, other organic substances and materials as operations with products.

Therefore, if the above requirements are met, manure produced at livestock enterprises can be considered a product. The implementation of the requirements for the transfer of waste (manure) into a product (organic fertilizer) requires the improvement of technical means for recycling organic waste [4-6]. The current state of development of technical means for recycling organic waste was carried out on the basis of a systematic analysis of literature sources and the authors' own research.

In the production of livestock products abroad, special attention is paid to reducing emissions of ammonia and other gases into the atmosphere. In the Netherlands, pollution abatement is being tested in small pilot farms [7]. Similar experiments are being carried out in Denmark, where systems for evaluating the use of protein in cattle feed and their influence on the release of ammonia are additionally investigated [8]. Considerable attention is paid to the research of multistage purifiers to reduce emissions of harmful substances at pig breeding enterprises [9]. In European countries, studies are underway to remove groups of microorganisms that reduce ammonia emissions at poultry farms [10]. The most effective direction is the recycling of organic waste from livestock and poultry farming into organic fertilizers, both independently and together with organic waste from plant growing (straw, not the grain part of other crops).

\section{Results}

The increase in the number of animals and poultry has led to the accumulation of large volumes of manure and droppings, the places of accumulation of which pose a threat to the surrounding flora and fauna, due to the fact that there is a large amount of pathogenic microflora in fresh manure and poultry $[3,11]$. Scientists of the former USSR and foreign specialists in the 70s-80s of the XX century actively developed technologies for processing all types of manure and dung into organic fertilizers and technical means for their implementation. With regard to large livestock and poultry enterprises producing liquid manure and droppings, technologies for mechanical separation into solid and liquid fractions have been developed, followed by the production of solid and liquid organic fertilizers on their basis. When processing semi-liquid manure and droppings, preference was given to compost production technologies using various moisture absorbers (straw, peat, etc.). Litter manure, as a rule, was processed according to the traditional technology: accumulation, bumping, periodic overburden, application to the field.

Figure 1 shows a technological scheme for the recycling of liquid organic waste based on liquid manure. 


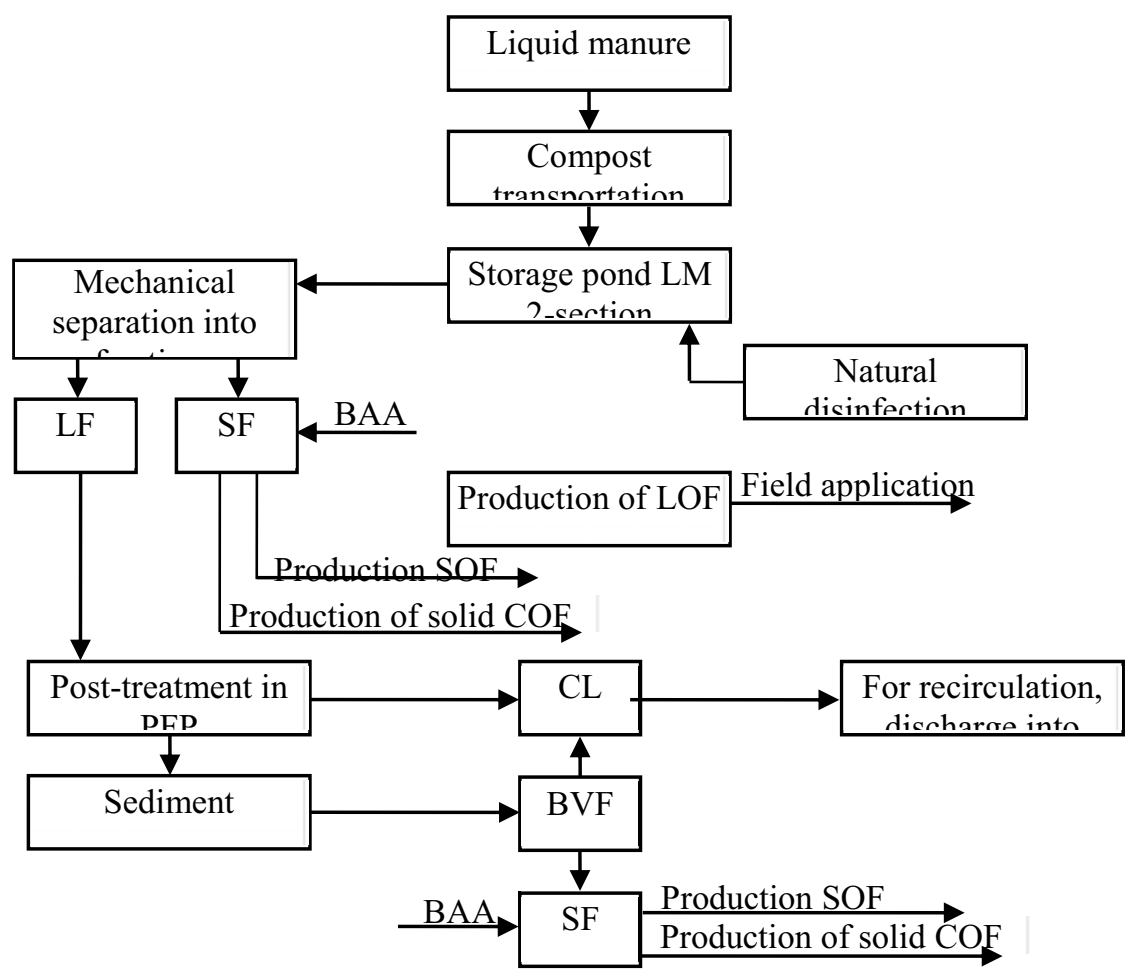

$\mathrm{LM}$ - liquid manure; $\mathrm{LF}$ - liquid fraction; $\mathrm{SF}$ - solid fraction; $\mathrm{CL}$ - clarified liquid;

PFP - pressure flotation plant; BVF - belt vacuum filter;

SOF - solid organic fertilizer; LOF - liquid organic fertilizer

Fig. 1. Process flow diagram of liquid manure recycling

Liquid manure is accumulated in lagoons, where it is biothermal disinfected for a set of keeping it for 12 months. After that, liquid organic fertilizer is applied to the field, as a rule, for forage crops with doses up to $400 \mathrm{~m} 3$ / ha. For pumping liquid manure and applying liquid organic fertilizers, it is necessary to increase the reliability of the operation of pumping stations and pumping equipment $[12,13]$. Efficient operation of pumping stations for pumping liquid manure is ensured by local mixing it at the point of intake by the pump using a device that converts wind energy into mechanical energy, thereby mixing layers of manure in a limited volume, bringing the mixture to a homogeneous state. The proposed device is a Savonius wind turbine with a vertical axis of rotation, located on a floating platform. The wind, acting on the blades, rotates a vertical shaft with rows of blades immersed in the manure. The blades in the process of rotation provide the lifting of liquid manure from the lower layers upwards, providing mixing of the upper (crust), middle (liquid) and lower (sediment) layers until a homogeneous state. The device operates at a wind speed of more than $3 \mathrm{~m} / \mathrm{s}$, which is observed at any latitude and at any time of the year.

The separation of manure into solid and liquid fractions and their subsequent use as solid and liquid organic fertilizers is promising. Filtering and settling centrifuges, vibration filters, vibrating screens, arc screens, filter presses and other equipment are used as mechanical separators $[3,14,15]$.

The solid fraction is formed into piles for further biothermal disinfection. To accelerate the process of biothermal disinfection, it is necessary to perform three main operations. 
Operation 1. Burts must be formed strictly orienting from east to west. In this case, almost the entire surface of the piles is uniformly illuminated by the sun during its full observed passage through the celestial sphere during daylight hours. At the same time, the slopes of the shoulder are covered with a black dye chemically passive pigment, which, due to thermal solar energy, which in the middle latitudes of Russia has a flow rate of up to 0.8 $\mathrm{kW} / \mathrm{m} 2$ in summer, and up to $0.5 \mathrm{~kW} / \mathrm{m} 2$ in winter, allows you to heat the surface of the shoulder, commensurate with the surface of an absolutely black body, to a temperature of 34 to $72^{\circ} \mathrm{C}$. The method promotes heating of the collar from the outside, and also provides a decrease in heat loss through the collar surface. The pile heated to $65-70{ }^{\circ} \mathrm{C}$ is kept in the specified parameters for up to 96 hours (4 days), after which the disinfection of manure is considered complete.

Operation 2. Provides for the use of biologically active additives (BAA), which not only improve the quality of the produced organic fertilizers, but also contribute in a short time (after 1.5-2.0 hours in the summer and 3.0-4.5 hours in winter) to heat the manure pile, thereby accelerating the process of its biothermal disinfection. The dietary supplement is introduced with a dose of $0.5 \%$ of the mass of processed heap [3]. The use of dietary supplements accelerates the transformation of manure into organic fertilizer, and in terms of the content of humus, nitrogen, phosphorus and potassium converts them into the category of concentrated organic fertilizers (COF), which in terms of the content of organic matter are significantly superior to traditional organic fertilizers. The application rate of COF is from 1 to $4 \mathrm{t} / \mathrm{ha}$, while traditional solid organic fertilizers are applied at doses from 40 to $60 \mathrm{t} / \mathrm{ha}$.

Operation 3. The effect of the use of dietary supplements depends on the quality of their distribution over the volume of the pile. For this purpose, as a rule, foreign-made refuellers are used (in Russia, their production has not yet been established). To control the process of biothermal disinfection of the manure pile, a device is proposed that, in a dynamic mode, allows one to determine the physical and mechanical parameters (heating temperature, humidity at control points) that affect the process of preparation of the COF.

The basic machine for the implementation of this operation is a self-propelled turner of collars of the SVB brand (made in Germany, China and other countries). The self-propelled turner (re-turner) is additionally equipped with a device for feeding liquid dietary supplements into the manure mass and with devices for controlling the manure processing process. Simultaneously with the formation of the pile, dietary supplements are introduced. After 4-6 hours, the temperature and moisture content of the manure is measured at the beginning, middle and end of the pile with simultaneous mixing of the manure mass (Figure 2). 


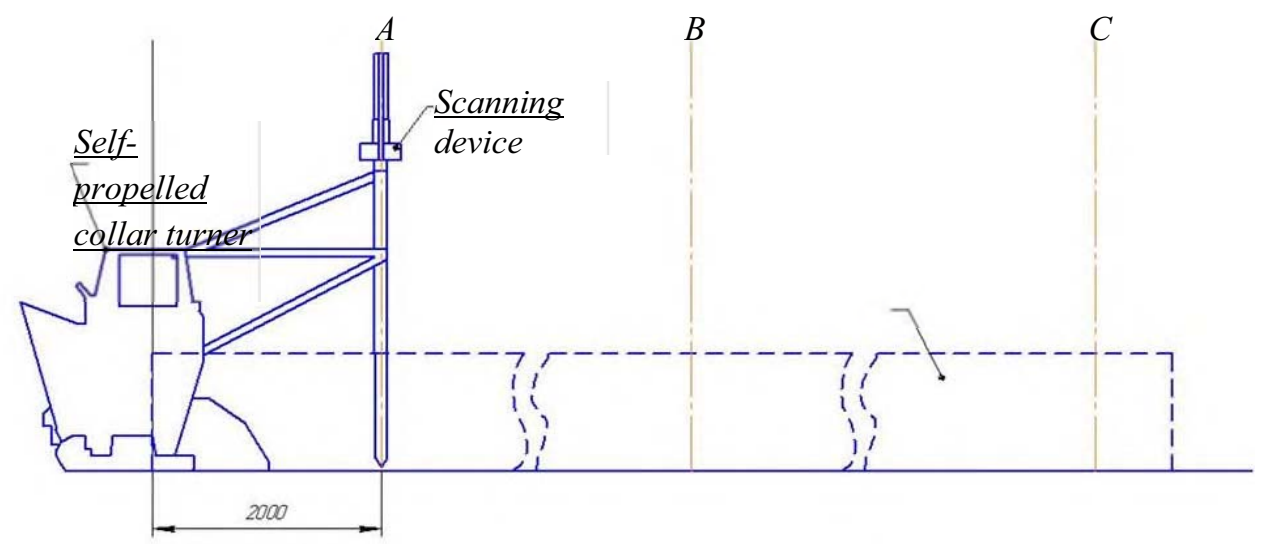

Fig. 2. Diagram of the process of controlling the maturation of the manure heap

The device works as follows. The self-propelled collar turner approaches control point A at the beginning of the collar, the edge of which is determined by means of a laser beam emitted by a laser diode. The on-board computer, located in the operator's cab, gives a signal to turn on the electric motor in the scan frame-lowering mode. After the limit switch of the lower position of the frame is triggered, the on-board computer starts the program for polling the temperature and humidity sensors. After saving the obtained values of temperature and humidity, these parameters are coordinated through the GlobalPositionningSistem satellite communication system and remain in the memory of the on-board computer. After lifting, the sensors, the agitator moves to the next point, control point $\mathrm{C}$. The process ends by scanning the parameters at point $\mathrm{C}$.

When the temperature at the control points is less than $65^{\circ} \mathrm{C}$ and the humidity is more than $70 \%$, the measurement process is repeated after 8 hours with simultaneous mixing of the pile. Measurements of these indicators are repeated every 8 hours until stable temperature values of more than $65^{\circ} \mathrm{C}$ and humidity of less than $70 \%$ are achieved. After that, after 24 hours, the disinfection process is considered complete and the resulting solid COF is ready for application to the field.

Figure 3 shows a scheme for recycling semi-liquid and solid manure as solid organic fertilizers.

It is advisable to compost the semi-liquid manure produced at livestock enterprises with a moisture content of $86-92 \%$ with a desiccant material (in the south of Russia it is straw). Composting allows you to get solid organic fertilizers according to the technologies described above when processing solid fraction of manure. With the introduction of dietary supplements, it is possible to produce solid COF in the same way as in the processing of bedding manure [3]. 


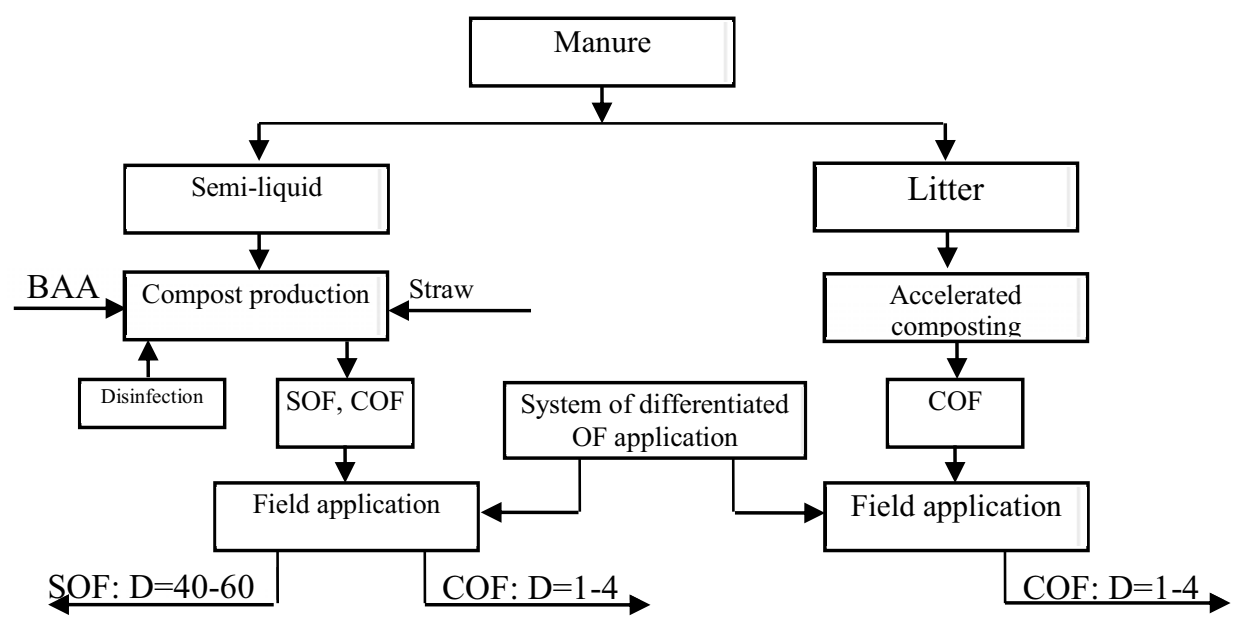

Fig. 3. Technological scheme for recycling semi-liquid and solid manure in precision farming systems

Trends in the development of technical means for recycling organic waste (see Fig. 1, 3) provide for the improvement of their working bodies, taking into account the differentiated application of organic fertilizers within the boundaries of the whole field. Studies carried out by Russian scientists have shown that within the boundaries of one field (the area of fields in the Southern Federal District is 80-100 hectares), fluctuations in nitrogen, phosphorus and potassium in the topsoil are up to $300 \%$ [16], that is, in some areas of the field there is a significant over-excess of certain components, while others are not enough. To level the soil fertility, it is necessary to take a cartogram of the field according to the content of nutrients in the production layer of the soil and the availability of technical means for selectively applying the required types and doses of fertilizers. Leveling of soil fertility contributes to obtaining stable yields of grain crops and, most importantly, trouble-free operation of combines during their harvesting due to the presence of a homogeneous mass of harvested plants along the entire path of the combine.

The task of differentiated fertilization is solved by mapping the variable chemical composition of the fields and, based on these maps, with the help of precise driving of field units applying fertilizers, the latter, using control using GPS, GLONASS systems, fertilizers are applied to the soil in adequate quantities. This is a cumbersome and low-precision technology. The proposed technology consists in the determination of nutrients in the soil using special gas laser analyzers (scanners) installed in the front of the fertilizer application. The obtained data are entered into the on-board computer of the tractor. In real time, on the basis of commands from the onboard computer, the required doses of fertilizers are introduced, taking into account the quantization step [16].

It should also be noted that there are many other technologies for recycling organic waste, such as the production of biogas by means of biogas plants on an industrial scale [3, $15]$ and for small volumes in the far north [17-18]. Technologies for processing organic raw materials by vermicomposting are actively cultivated in Russia and European countries [1921]. The resulting product - vermicompost - is in demand in the production of organic products.

Many researches of scientists in the development of machines for recycling organic raw materials are aimed at reducing energy consumption and metal consumption [3, 22-23]. 


\section{Discussion}

The considered technologies for recycling organic waste from agricultural production provide for the availability and development of technical means for their implementation. Fresh organic waste, having in its composition the nutrients and trace elements necessary for plants, pose a direct threat to the environment due to the presence in them of a large amount of pathogenic microflora. On the other hand, the decrease in soil fertility is due to the lack of organic fertilizers. Reducing the negative impact of manure on the environment is possible with the use of modern achievements of agrarian science and related sectors of the national economy: application of technologies for accelerated composting of semiliquid and solid manure using dietary supplements; separation of liquid manure, solid and liquid fractions and their separate processing using dietary supplements. All this makes it possible to obtain solid and liquid concentrated organic fertilizers, which are applied to the field at doses from 1 to $4 \mathrm{t} / \mathrm{ha}$. The introduction of traditional solid and liquid organic fertilizers with recommended doses (solid - 40-60 t/ha, liquid - up to $400 \mathrm{~m} 3 /$ ha) is not economically justified, since the resulting increase in yield does not cover the costs of their production and application.

The basic technical means for the implementation of these technologies are:

1. Low-energy devices for local mixing of liquid manure at the points of its intake by pumping units, based on the use of wind energy (Savonius principle).

2. Collar turner with devices for introducing liquid biologically active additives with simultaneous mixing, control of the main parameters of the heap ripening to obtain solid concentrated organic fertilizers.

3. In organic farming systems, an important role is assigned to the leveling of soil fertility in the boundaries of the whole field by means of differentiated fertilization. For this, an improved system is being developed for scanning nutrients in the topsoil by means of gaslaser analyzers installed in the front of the tractor, accumulating information in the onboard computer of the tractor. By sending a command by a computer to the actuating mechanisms of the spreading device, the latter in certain areas of the field apply the required doses and types of fertilizers.

It can be seen from the presented material that the development of technical means for recycling organic waste in the agricultural sector makes it possible to distinguish three main trends:

- the ability to interact with livestock and crop production. The connecting link of the industries is the soil, as the main source of food for the population and for animal feed;

- conversion of raw materials (organic waste from animal husbandry and crop production) into a product in the form of high-quality concentrated organic fertilizers necessary to restore soil fertility;

- digitalization of technological processes for the production of COF and their differentiated application to the field by scanning the qualitative composition of nutrients in the production layer of soil.

\section{Conclusions}

The presented directions for the development of technical means for recycling organic waste in the agricultural sector allow organizing waste-free production of livestock and crop products, increasing their profitability by leveling soil fertility, thereby guaranteeing the economic stability of enterprises and environmental safety in places of accumulation of raw materials. The main trends in the development of technical means are in the effective interaction of animal husbandry and crop production, the transfer of organic waste into a product, digitalization of technological processes and machines for their implementation 
using modern technologies for collecting information and processing it and applying it in the processes under consideration.

\section{References}

1. S. Volkov, D. Shapovalov, P. Klyushin, V. Shirokova, A. Khutorova, International Multidisciplinary Scientific GeoConference SGEM, 3.2, 17, 209-216 (2017) DOI: $10.5593 /$ sgem $2017 / 32 /$ S13.028

2. J. Ragulina, International journal for quality research, 4, 947-965 (2019)

3. A. Bondarenko, L. Kachanova, E. Lipkovich, Journal of Environmental Management and Tourism, 1(25), 9, 5-11 (2018) DOI: 10.14505/jemt.v9.1(25).01

4. A. Briukhanov, E. Vasilev, N. Kozlova, S. Lukin, Innovative solutions for sustainable management of nitrogen. Conf. Proc., 126 (2017)

5. A. Briukhanov, E. Vasilev, E. Shalavina, O. Kucheruk, IOP Conference Series: Earth and Environmental Science, 042001 (2017) DOI: 10.1088/1755-1315/87/4/042001

6. A. Murskii, I. Shigapov, Chemical and Petroleum Engineering, 1-2(48), 84-86 (2012) DOI: $10.1007 / \mathrm{s} 10556-012-9578-3$

7. A. Bryukhanov, E. Shalavina, E. Vasiliev, A. Valge, Engineering for rural development, 19, 645-652 (2020) DOI: 10.22616/ERDev.2020.19.TF144

8. J. Oenema, Wageningen Journal of Life Sciences, 58, 39-48 (2011)

9. D. Beliaev, et al., E3S Web of Conferences, 164, 06029 (2020) doi: 10.1051/e3sconf/202016406029

10. Y. Zhao, A. J A Aarnink, M. C.M. De Jong, Transactions of the ASABE, 54, 285-293 (2011)

11. S. Tarasyants, K. Degtyareva, J. Urzhumova, Periodico Tche Quimica, 1(15), 89-97 (2018)

12. V. Druzyanova, S. Petrova, M. Okhlopkova, G. Soloviov, M. Sleptsova, Ecology, Environment and Conservation, 4(23), 2118-2124 (2017)

13. P. Pashkov, S. Tarasyants, D. Efimov, PeriodicoTche Quimica, 1(15), 55-66 (2018)

14. S. Rudov, V. Shapiro, I. Grigorev, O. Kunitskaya, V. Druzhanova, G. Kokieva, A. Filatov, M. Sleptsova, A. Bondarenko, D. Radnaed, International Journal of Civil Engineering and Technology, 1(10), 2052-2071 (2019)

15. S. Tarasyants, O. Rakhnyanskaya, Y. Tsarevsky, K. Degtyareva, J. Urzhumova, Asia Life Sciences, 1(28), 183-194 (2019)

16. I. Lipkovich, I. Egorova, N. Petrenko, A. Gaida, Journal of Mechanical Engineering Research and Developments, 3(42), 10-14 (2019) DOI: 10.26480/jmerd.03.2019.10.14

17. V. Druzhanova, S. Petrova, N. Khiterkheeva, I. Bardamova, T. Gergenova, E3S Web of Conferences. XIII International Scientific and Practical Conference "State and Prospects for the Development of Agribusiness - INTERAGROMASH 2020”, 12012 (2020) DOI: $10.1051 / \mathrm{e} 3$ sconf $/ 202017512012$

18. V. Druzyanova, S. Petrova, M. Okhlopkova, Y. Sergeev, DYNA, 4, 398-403 (2018) DOI: $10.6036 / 8598$

19. I. Lipkovich, I. Egorova, N. Petrenko, N. Sergeev, S. Pyatikopov, Asia Life Sciences, 1(28), 205-228 (2019)

20. S. Pridvizhkin, M. Vyguzova, O. Bazhenov, IOP Conference Series: Materials Science and Engineering, 012165 (2017) DOI: 10.1088/1757-899X/262/1/012165 
21. M. Kuznetsova, A. Khadzhidi, E. Kuznetsov, Y. Poltorak, Scientific Journal of the Russian Research Institute of Melioration Problems, 4(32), 77-88 (2018) DOI: 10.31774/2222-1816-2018-4-77-88

22. B. Meskhi, N. Limarenko, V. Zharkov, B. Shapoval, Bulletin of the Don State Technical University, 4, 129-135 (2017) DOI: 10.23947/1992-5980-2017-17-4-129135

23. N. Byshov, I. Uspensky, I. Yukhin, N. Limarenko, IOP Conference Series: Earth and Environmental Science. Voronezh State Agrarian University named after Emperor Peter the Great, 012069 (2020) DOI: 10.1088/1755-1315/422/1/012069 